\title{
Science/Education Portraits III: Perceived Prevalence of Data Fabrication and/or Falsification in Research
}

\author{
Maurice HT Ling $1,2 *$ \\ ${ }^{1}$ Colossus Technologies LLP, Republic of Singapore \\ ${ }^{2}$ HOHY PTE LTD, Republic of Singapore
}

Submission: October 15, 2018; Published: December 07, 2018

*Corresponding author: Maurice HT Ling, Colossus Technologies LLP, 8 Burn Road \#15-13, TRIVEX, Singapore 369977, Republic of Singapore

\begin{abstract}
Data fabrication or falsification are considered as "deadly sins" with high impact, above plagiarism, on scientific truth and public confidence. What is the estimated prevalence of data fabrication or falsification? A meta-survey published a decade ago estimated $14.12 \%$ of respondents having knowledge of a colleague who fabricated or falsified research data, or who altered or modified research data. This mini-review updates this meta-survey by examining surveys from 2009 to 2018. Results suggests that 17.7\% of responses indicated knowledge of fellow scientist's acts of data fabrication or data falsification. This is consistent with that of a decade ago, which suggests a critical need to address the worst type of research misconduct - data fabrication and falsification.
\end{abstract}

Keywords: Research integrity, Research misconduct, Fabrication, Falsification

\section{Introduction}

There is no doubt that research misconduct does occur, from the cautionary tale of Piltdown Man [1] to potential fraudulent reporting [2] to the more recent high-profile cases of Yoshihiro Sato [3], Steven A. Leadon [4], and Woo Suk Hwang [5]. Research misconduct does not only occur in biological sciences but other science as well; such as, physics [6], and chemistry [7]. Although research misconduct pre-dates the $20^{\text {th }}$ century [8]; studies into the prevalence of research misconduct, especially on data fabrication and/or falsification in biological sciences, only exist post-1990s [9].

The prevalence of research misconduct is a perennial question and Richard Smith [10] quoted Mike Farthing for estimating about one serious case a year in each major institution in Britain. In an early survey, Geggie D [9] reported 10.8\% (21 out of 194 respondents) having first-hand knowledge of scientists or doctors intentionally altering or fabricating data for publication, which may lead to loss of confidence and future participation by the public in clinical research [11]. A survey by Bouter et al. [12] ranked data fabrication and data falsification as having highest impact on scientific truth, above plagiarism.

In this mini-review, existing surveys on research misconduct were examined to determine the prevalence of data fabrication and/or data falsification in biological sciences. Fanelli D [13] defines data fabrication as invention of data or cases, and data falsification as wilful distortion of data or results. Hence, data fabrication and data falsification is not plausible to be deemed as honest mistakes or scientific disagreement [14], especially in the case of data fabrication.

\section{Surveys in Research Data Fabrication and/or Falsifica-} tion

Fanelli D [13] performed a first meta-survey on 21 published surveys (15 surveys from USA, 3 surveys from UK, 2 surveys with multinational sample, and 1 survey from Australia) between 1987 and 2008, amounting to 11647 respondents. Between 5.2\% and $33.3 \%$ (with weighted estimate of $14.12 \%$, implying 1644 respondents) of respondents replied affirmatively to having personal knowledge of a colleague who fabricated or falsified research data, or who altered or modified research data. The $95 \%$ confidence interval was calculated to be between 9.91\% 11152 respondents) to $19.72 \%$ (2297 respondents). Since Fanelli D [13] analysed surveys published to 2008 inclusive, 10 published surveys from 2009 to 2018 are reviewed here:

I. Tavare A (15) reported on a British Medical Journal (BMJ) email survey of 9036 academics and clinicians, in United Kingdom, whom had either published in BMJ or acted as reviewers and received a response rate of $31 \%$ (2801 respondents). If these 2801 respondents, 13\% (364 respondents) admitted knowledge of colleagues "inappropriately adjusting, excluding, altering, or fabricating data" for publication. 
II. Sheldon T [16] reported a published survey on Dutch general practitioners' specialists from hospital and social care (original survey published in Medics Contact, http://medischcontact.artsennet.nl/Nieuws-26/archief-6/ Tijdschriftartikel/113385/Liever-lezendan-doen.htm), in which 809 of 1635 (49.5\%) responded. Of these 809 respondents, $15 \%$ (121 respondents) believed that they had witnessed "close hand scientific results that were invented" (data fabrication) and 22\% (178 respondents) believed that they had witnessed "close hand research data that had been selected or statistically treated to achieve significant results" (which may constitute data falsification).

III. Grieneisen \& Zhang [17] examined 4232 article retractions from 1928-2011 across 1796 unique journal titles and 3631 (85.8\%) retractions were given justifications. found 602 $(16.6 \%)$ articles were retracted due to fraudulent or fabricated results. The authors found a rise in the percentage of retractions from 1990 onwards, based on PubMed records or Web of Science records by publication year.

IV. Hofman et al. [18] surveyed 262 postgraduate students attending introductory PhD-courses across medical faculties in Norway in 2010/2011 and 189 (72.1\%) anonymous questionnaires were returned. Of the respondents, $29.2 \%$ (55 respondents) and $23.8 \%$ (45 respondents) heard about someone whom during the last 12 months, both nationally and internationally, whom had fabricated data or falsified data respectively. Significantly, one respondent had reported pressure to fabricate or falsify data.

V. Okonta \& Rossouw [19] surveyed 133 out of 150 (88.7\% respondents) Nigerian researchers attending the conference. Of the 133 respondents, 120 (90.2\%) perceived that data fabrication occurred in their workplace and 108 (81.2\%) perceived that selective omission of data (which may constitute data falsification) occurred in their workplace. However, only about half of the respondents were aware of at least one case of misconduct in their institute within the last 5 years.

VI. Hofmann et al. [20] surveyed 201 (90.5\% respondents from 222 questionnaires issued) post-graduate students enrolled in the $\mathrm{PhD}$ program at Karolinska Institute in Stockholm and the University of Oslo. Of the 201 respondents, 105 (91.3\% respondents) were from Karolinska Institute and 96 (89.7\% respondents) were from University of Oslo. $27.6 \%$ (29 respondents) from Karolinska Institute and 25.3\% (24 respondents) from University of Oslo heard about someone whom during the last 12 months, both nationally and internationally, whom had fabricated data; which gives a total of 53 (26.4\%) respondents. 29.8\% (31 respondents) from Karolinska Institute and $22.3 \%$ (21 respondents) from University of Oslo heard about someone whom during the last 12 months, both nationally and internationally, whom had falsified data; which gives a total of 52 (25.9\%) respondents. Importantly, one respondent from University of Oslo reported to have falsified data in the last 12 months.
VII. Looi et al. [21] surveyed 151 journals across Asia Pacific Association of Medical Editors and received 54 (35.8\%) responses. Of the 54 journals, 16 (29\%) journals experienced data falsification and 15 (27\%) journals experienced fraudulent data/ image manipulation.

VIII. Pupovac et al. [22] surveyed 1232 Croatian scientists at the University of Rijeka in 2012/2013 with 237 (19.2 \%) respondents. Of the respondents, 69 (29.1\%) observed data falsification in fellow scientists and 46 (19.4\%) observed data fabrication in fellow scientists. More importantly, 22 (9.3 \%) respondents admitted to data falsification and 9 (3.8\%) respondents admitted to data fabrication.

IX. Godecharle et al. [23] surveyed 2021 scientists in Belgium; of which, 1766 were from universities and 255 from industry. 617 (34.9\%) and 100 (39.2\%) responses were obtained from universities and industry respectively, yielding a final response rate of $35.5 \%$ (717 responses). Collectively, 4\% (29 respondents) and $12 \%$ (86 respondents) reported to have observed data fabrication and data falsification respectively, with as high as $40 \%$ (287 respondents) reported observing data selection. More importantly, one respondent from the industry admitted to data fabrication, and as high as $15 \%$ of all respondents (108 respondents) admitted to data selection.

X. Felaefel et al. [24] collected 278 usable surveys out of 348 submitted surveys from students and academics in Cairo University, American University in Cairo and Suez Canal University in Egypt, Royal College of Surgeons in Ireland, Medical University of Bahrain, and Ain Wazein Hospital in Lebanon, using SurveyMonkey via recruitment email or hand distribution of survey forms at Cairo University, Egypt. 72 (25.9\%) and 65 (23.4\%) of 278 respondents had knowledge of data fabrication and data falsification (changing data without mentioning) in colleagues respectively. Of the 224 self-admission, 21 (9.7\%) and $21(9.7 \%)$ admitted to data fabrication and data falsification respectively.

Collectively from these 10 published surveys, 7 surveys segregated between knowledge of fellow scientist's acts of data fabrication and data falsification. These 7 surveys comprised of 2654 responses out of 5870 surveyed - response rate of $45.2 \%$. Of which, $496(18.7 \%)$ and $603(22.7 \%)$ respondents reported knowledge of fellow scientist's acts of data fabrication and data falsification respectively. Taking all 10 published surveys into consideration, 9140 responses out of 19289 were gathered (response rate of 47.4\%); of which, 1622 (17.7\%) responses indicated knowledge of fellow scientist's acts of data fabrication or data falsification.

\section{Concluding Remarks}

Data fabrication or falsification are considered as "deadly sins" with the highest impact on scientific truth [12], leading to potential loss of public confidence [11]. Yet, proportion of published articles retracted dur to fraudulent or fabricated results appears to be increasing [17]. A decade ago, Fanelli D [13] 
reported an estimated $14.12 \%$ of respondents having knowledge of a colleague who fabricated or falsified research data, or who altered or modified research data the first meta-survey done in this field. This mini-review suggests that $17.7 \%$ of responses indicated knowledge of fellow scientist's acts of data fabrication or data falsification. This result is within $95 \%$ confidence interval reported by Fanelli D [13], suggesting that this trend has not declined over 2 decades. This suggests a critical need to address the worst type of research misconduct - data fabrication and falsification.

\section{Conflict of Interest}

The author declares no conflict of interest.

\section{References}

1. De Groote I, Flink LG, Abbas R, Bello SM, Burgia L, et al. (2016) New genetic and morphological evidence suggests a single hoaxer created 'Piltdown man. R Soc Open Sci 3(8): 160328.

2. Smith KA (2005) Wanted, an Anthrax vaccine: Dead or Alive? Med Immunol 4(1): 5.

3. Kupferschmidt K (2018) Tide of lies. Science 361(6403): 636-641.

4. Check E (2005) Retracted papers damage work on DNA repair. Nature 435(7045): 1015.

5. Cyranoski D (2009) Woo Suk Hwang convicted, but not of fraud. Nature 461(7268): 1181.

6. Mizubayashi H (2009) University of Tsukuba defends professor's dismissal. Physics Today 62(2): 12.

7. Zhong H, Duan S H, Hong Y P, Li ML, Liu YQ et al. (2009) Retraction of articles by H. Zhong et al. Acta Crystallogr Sect E Struct Rep Online. 66(Pt 1): e11-12.

8. Lafollette MC (2000) The Evolution of the "Scientific Misconduct" Issue: An Historical Overview (44535C). Experimental Biology and Medicine 224(4): 211-215.

9. Geggie D (2001) A survey of newly appointed consultants' attitudes towards research fraud. Journal of Medicial Ethics. 27(5): 344-346.

10. Smith R (2006) Research misconduct: the poisoning of the well. J R Soc Med 99(5): 232-237.

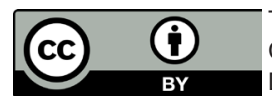

This work is licensed under Creative Commons Attribution 4.0 Licens

DOI: 10.19080/AIBM.2018.11.555824
11. McIntyre OR, Kornblith AB, Coburn J (1996) Pilot Survey of Opinions on Data Falsification in Clinical Trials. Cancer Investigation 14(4): 392395.

12. Bouter LM, Tijdink J, Axelsen N, Martinson BC, Ter Riet G (2016) Ranking major and minor research misbehaviors: results from a survey among participants of four World Conferences on Research Integrity. Research Integrity and Peer Review 1:17.

13. Fanelli D (2009) How many scientists fabricate and falsify research? A systematic review and meta-analysis of survey data. PLoS ONE 4(5): e5738.

14. Resnik DB, Stewart CN (2012) Misconduct versus honest error and scientific disagreement. Account Res 19(1): 56-63.

15. Tavare A (2012) Scientific misconduct is worryingly prevalent in the UK, shows BMJ survey. BMJ: British Medical Journal: 344.

16. Sheldon T (2012) Survey of Dutch doctors finds evidence of widespread research misconduct. BMJ 344: e2898.

17. Grieneisen ML, Zhang M (2012) A comprehensive survey of retracted articles from the scholarly literature. PLoS ONE 7(10): e44118.

18. Hofmann B, Myhr AI, Holm S (2013) Scientific dishonesty: a nationwide survey of doctoral students in Norway. BMC Med Ethics 14: 3.

19. Okonta PI, Rossouw T (2014) Misconduct in research: a descriptive survey of attitudes, perceptions and associated factors in a developing country. BMC Med Ethics 15: 25.

20. Hofmann B, Helgesson G, Juth N, Holm S (2014) Scientific Dishonesty: A Survey of Doctoral Students at the Major Medical Faculties in Sweden and Norway. J Empir Res Hum Res Ethics 10(4): 380-388.

21. Looi LM, Wong LX, Koh CC (2015) Scientific misconduct encountered by APAME journals: an online survey. Malays J Pathol 37(3): 213-218.

22.Pupovac V, Prijić-Samaržija S, Petrovečki M (2017) Research Misconduct in the Croatian Scientific Community: A Survey Assessing the Forms and Characteristics of Research Misconduct. Sci Eng Ethics 23(1): 165-181.

23. Godecharle S, Fieuws S, Nemery B, Dierickx K (2017) Scientists Still Behaving Badly? A Survey Within Industry and Universities. Sci Eng Ethics.

24. Felaefel M, Salem M, Jaafar R, Jassim G, Edwards H, et al. (2018) A CrossSectional Survey Study to Assess Prevalence and Attitudes Regarding Research Misconduct among Investigators in the Middle East. J Acad Ethics 16(1): 71-87.

\section{Your next submission with Juniper Publishers will reach you the below assets}

- Quality Editorial service

- Swift Peer Review

- Reprints availability

- E-prints Service

- Manuscript Podcast for convenient understanding

- Global attainment for your research

- Manuscript accessibility in different formats

( Pdf, E-pub, Full Text, Audio)

- Unceasing customer service

Track the below URL for one-step submission https://juniperpublishers.com/online-submission.php 